\title{
Comparison of the Effect of Ranibizumab and Triamcinolone Acetonide in Diabetic Macular Edema with Epiretinal Membrane in Pseudophakic Patients
}

\author{
Ahmed E. Daifalla ${ }^{\mathrm{a}}$, Ahmed A. Tabl ${ }^{\mathrm{a}}$, Marwa A. ElFouly ${ }^{\mathrm{b}}$, Mohamed M. Rezk ${ }^{\mathrm{b}}$
}

\footnotetext{
a Department of Ophthalmology, Faculty of Medicine Benha University, Egypt . ${ }^{\mathrm{b}}$ Department of Ophthalmology, Research Institute of Ophthalmology, Giza, Egypt.
}

Correspondence to: Mohamed M. Rezk, Department of Ophthalmology, Research Institute of Ophthalmology, Giza, Egypt.

Email:

m7mdmbrk@gmail.com

Received: 12 July 2021

Accepted: 16 August 2021

\begin{abstract}
:
Background: Macular edema is considered the main cause of visual loss in diabetic retinopathy patients. Aim: The aim of this study is to compare the effectiveness of intravitreal Ranibizumab and Triamcinolone acetonide in management of diabetic macular edema with epiretinal membrane in pseudophakic patients. Methods: In this prospective observational study we compared the efficacy of intravitreal Ranibizumab and Triamcinolone acetonide on 35 eyes of 28 pseudophakic patients with DME with ERM. BCVA, IOP and CMT were recorded to patients before injection and then at 1st, 4th, 8th and 12th week after injection. Results: BCVA improved from $0.5(0.3-1.4)$ to reach $0.2(0-0.9)$ LogMAR at 12th week postinjection in the Ranibizumab group and improved from $0.6(0.5-1.6)$ to $0.4(0.1-1.5)$ LogMAR at 12th week postinjection in TA group. IOP changed from baseline of $19.06 \pm 2.9$ to $23.17 \pm 2.68$ at 1 st week reaching $19.56 \pm 1.72$ at 12 th week ( $\mathrm{p}<0.001$ ) in Ranibizumab group, and changed from baseline of $20.0 \pm 2.03$ to $23.76 \pm 2.31$ at 1 st week reaching $20.0 \pm 1.73$ at 12 th week in TA group. CMT changed from $414.11 \pm 130.44$ preinjection to $251.44 \pm 67.22$ at 12 th week postinjection in the Ranibizumab group, and changed from
\end{abstract} $499.0 \pm 175.57$ preinjection to $340.24 \pm 135.79$ at 12 th week postinjection in TA group. Conclusion: Our data on the overall treatment response assessed as a change in BCVA, IOP and CMT are in accordance with previous studies, which have proven the clinical efficacy of Ranibizumab and Triamcinolone acetonide for DME therapy.

Key words: Ranibizumab, Triamcinolone acetonide, DME, ERM, pseudophakic. 


\section{Introduction:}

Macular edema is the main cause of visual loss in diabetic retinopathy patients $^{1}$. The Early Treatment of Diabetic Retinopathy Study (ETDRS) indicates that focal or grid laser photocoagulation for the clinically significant macular edema effectively reduces the risk of moderate vision loss ${ }^{2}$. Later studies showed that grid laser photocoagulation has limited efficacy, and also may cause decreased vision because of progressive macular scar and subretinal fibrosis ${ }^{3}$.

At present, there have been several therapies for the treatment of diabetic macular edema (DME) such as intravitreal steroids and anti-vascular endothelial growth factor (VEGF) injections . Ranibizumab and bevacizumab are two main anti-VEGF agents for DME. Many studies have shown that intravitreal Ranibizumab (IVR) was effective for reducing $\mathrm{DME}^{4}$.Triamcinolone acetonide (TA) has anti-inflammatory and anti-angiogenic effect. Many reports have shown the usefulness of intravitreal TA (IVTA) in patients with $\mathrm{DME}^{5}$. With the increasing use of IVR and IVTA, it is of interest to know which agent is more effective and safe.

\section{Patients and methods:}

It is a multicenter; observational study that was conducted at Benha University Ophthalmology Department and Research Institute of Ophthalmology in the period from August 2019 to February 2021.

The study was carried out on 35 eyes of 28 patients with DME presented to Ophthalmology department of Benha University and Medical Retina department at Research Institute of Ophthalmology.

Ophthalmological examination findings were included; best-corrected visual acuity (BCVA) which was measured with the Snellen chart and then converted to $\log$ MAR, intraocular pressure (IOP) by Goldmann applanation tonometry. The diagnosis of diabetic retinopathy and macular edema was made with slit-lamp fundus examination and Retinal thickness measurement by Optical coherence tomography (OCT).

We included patients with retinal thickening of two or more disk areas involving some portion of the foveal avascular zone and diffuse fluorescein leakage involving the fovea and most of the macular area on fluorescein angiography, LogMAR BCVA of 0.5 or worse, Central macular thickness (CMT) greater than $300 \mu \mathrm{m}$ on OCT, Epiretinal 
membrane diagnosed clinically and by OCT and pseudophacic eyes.

We excluded patients which have previous therapies for macular edema, including grid-laser treatment, intravitreal injection of any drugs, and/or vitreous surgery. macular ischemia on fluorescein angiography, aphakic eye, Glycosylated hemoglobin (HbA1c) level above 10\%, History of glaucoma or ocular hypertension, pan retinal photocoagulation history shorter than 3 months, an ocular condition other than diabetes mellitus (DM) that might affect macular edema or alter visual acuity during the course of the study such as retinal vein occlusion, uveitis or other ocular inflammatory disease, macular degeneration, systemic corticosteroid therapy, history of thromboembolic event or current use of anticoagulants medication other than acetylsalicylic acid or uncontrolled hypertension.

Pars-plana Intravitreal injections were performed in the operating theatre, under sterile conditions. The $0.5 \mathrm{mg} / 0.05 \mathrm{~mL}$ of Ranibizumab (Lucentis manufactured by Novartis) was injected into 18 eyes of patients of the study, and $4 \mathrm{mg} / 0.1 \mathrm{~mL}$ of TA (Kenacort-A, $40 \quad \mathrm{mg} / \mathrm{mL}$ manufactured by GlaxoSmithKline), using non-filtering technique (sedimentation), was injected into 17 eyes of the other patients. All patients were examined for control 1 day after injection. Ofloxacin $0.3 \%$ drops was prescribed four times per day for a week.

According to the CMT values determined by OCT, TA and Ranibizumab were injected into the eye with thicker CMT of consecutive patients by turn to make possible equal conditions of macular edema between groups. Patients' visual acuity, CMT, IOP data were evaluated at $1,4,8,12$ weeks.

Informed consents were obtained from all participants. This study was conducted after approval of the ethics committee of research involving human subjects of Faculty of Medicine - Benha University.

Data analysis was performed using the software SPSS (Statistical Package for the Social Sciences) version 20. Quantitative variables were described using their means and standard deviations. Chi square test was used to compare the proportion of categorical data. Kolmogor $\neg 0 v-S m i r n o v$ (distribution-type) and Levene (homogeneity of variances) tests were used to verify assumptions for use in parametric tests, To compare means of two groups, independent sample $\mathrm{t}$ test was used when appropriate, Nonparametric test (Mann Whitney) was 
used to compare means when data was not normally distributed and to compare medians in categorical data, To compare change in continuous variable over two points of time, paired $t$ test (for parametric data) and Wilcoxon signed rank test (for non-parametric data) were used, To measure change over time, repeated measure ANOVA was used for normally distributed data and Friedman test was used for not normally distributed data. The level statistical significance was set at $\mathrm{P}<0.05$. Highly significant difference was present if $p \leq 0.001$.

\section{Results:}

There is statistically non-significant difference between the studied groups regarding age, gender or side of the lesion (Table 1).

As regard to BCVA, there is statistically non-significant difference between the studied groups regarding BCVA baseline, and at 4th week, and there is statistically significant difference between the studied groups regarding BCVA at 1st, 8th and 12th week, there is statistically significant change in BCVA among each group over time (Table 2), there is significant improvement in BCVA at 1st, 4th, 8th, and 12th week compared to baseline level in both groups, there is statistically significant difference between the studied groups regarding BCVA in the 8th and 12th week. However, there is non-significant difference between them in the 1st and 4th week.

As regard to IOP, there is statistically non-significant difference between the studied groups regarding IOP baseline, 1st, 4th , 8th and 12th week. There is statistically significant change in IOP among each group over time (Table 3), there was also significant increase in IOP at 1st, 4th and 8th week compared to baseline level while there is nonsignificant change at 12th week from baseline value among Ranibizumab group, there is significant increase in IOP at $1 \mathrm{st}$, and 4 th week compared to baseline level while there is nonsignificant change at 8th and 12th week from baseline value among Triamcinolone acetonide group, That may be explained by the difference in the volume of injected material between the two groups $0.05 \mathrm{~mL}$ of Ranibizumab and $0.1 \mathrm{~mL}$ Triamcinolone acetonide.

As regard to CMT, there is statistically non-significant difference between the studied groups regarding CMT baseline, and $1^{\text {st }} \quad$ week, there is statistically significant difference between the studied groups regarding CMT at $4^{\text {th }}, 8^{\text {th }}$ and $12^{\text {th }}$ week (significantly higher among 
patients receiving TA drug), there is statistically significant decrease in CMT among each group over time (Table 4), there is significant decrease in CMT at $1^{\text {st }}, 4^{\text {th }}, 8^{\text {th }}$, and $12^{\text {th }}$ week compared to baseline level in both groups. All the studied patients had decreased CMT in the $1^{\text {st }}$ and $4^{\text {th }}$ week. On the other hand, one patient out of those received Triamcinolone acetonide had increased CMT in the $8^{\text {th }}$ and $12^{\text {th }}$ week.

Table (1): Comparison between the studied groups regarding demographic data.

\begin{tabular}{lcccc}
\hline Parameter & \multicolumn{2}{c}{ Groups } & Test & \\
& $\begin{array}{c}\text { Ranibizumab drug } \\
\text { group } \\
\mathbf{N = 1 6}(\mathbf{0})\end{array}$ & $\begin{array}{c}\text { Triamcinolone } \\
\text { acetonide group } \\
\mathbf{N = 1 2}(\mathbf{\%})\end{array}$ & $\chi^{\mathbf{2} / \mathbf{t}}$ & $\mathbf{p}$ \\
\hline Gender: & $7(43.8)$ & $7(53.8)$ & 0.583 & 0.445 \\
Female & $9(56.2)$ & $5(46.2)$ & & \\
Male & & & 0.069 & 0.945 \\
Age (year): & $62.25 \pm 7.15$ & $62.08 \pm 4.91$ & & \\
Mean \pm SD & $48-72$ & $53-70$ & & \\
Range & &
\end{tabular}

$\chi^{2}$ Chi square test $t$ Independent sample $t$ test

Table (2): Comparison between the studied groups regarding BCVA over time.

\begin{tabular}{|c|c|c|c|c|}
\hline \multirow[t]{2}{*}{ BCVA } & \multicolumn{2}{|c|}{ Groups } & \multicolumn{2}{|c|}{ Test } \\
\hline & $\begin{array}{l}\text { Ranibizumab group } \\
\text { Median (range) }\end{array}$ & $\begin{array}{l}\text { Triamcinolone } \\
\text { acetonide group } \\
\text { Median (range) }\end{array}$ & $\mathbf{Z}$ & $\mathbf{p}$ \\
\hline Baseline & $0.5(0.3-1.4)$ & $0.6(0.5-1.6)$ & -1.865 & 0.062 \\
\hline $1^{\text {st }}$ week & $0.4(0.3-1.2)$ & $0.5(0.3-1.4)$ & -2.269 & $0.023 *$ \\
\hline $4^{\text {th }}$ week & $0.3(0.1-1.1)$ & $0.4(0.2-1.4)$ & -1.81 & 0.07 \\
\hline $8^{\text {th }}$ week & $0.2(0-0.9)$ & $0.4(0.2-1.3)$ & -2.852 & $0.004 *$ \\
\hline $12^{\text {th }}$ week & $0.2(0-0.9)$ & $0.4(0.1-1.5)$ & -3.094 & $0.002 *$ \\
\hline$P(\mathbf{E r})$ & $<0.001 * *$ & $<0.001 * *$ & & \\
\hline
\end{tabular}

Table (3): Comparison between the studied groups regarding IOP over time.

\begin{tabular}{lcccc}
\hline IOP & \multicolumn{2}{c}{ Groups } & Test \\
& Ranibizumab group & $\begin{array}{c}\text { Triamcinolone } \\
\text { acetonide group }\end{array}$ & t & p \\
\hline Mean \pm SD & $\mathbf{N}=\mathbf{1 6}(\boldsymbol{\%})$ & $\mathbf{N = 1 2 ( \% )}$ & & \\
Baseline & $19.06 \pm 2.9$ & $20.0 \pm 2.03$ & -1.11 & 0.275 \\
$\mathbf{1}^{\text {st }}$ week & $23.17 \pm 2.68$ & $23.76 \pm 2.31$ & -0.705 & 0.486 \\
$\mathbf{4}^{\text {th }}$ week & $20.78 \pm 1.99$ & $21.41 \pm 1.46$ & -1.07 & 0.292 \\
$\mathbf{8}^{\text {wh }}$ week & $20.28 \pm 1.71$ & $20.29 \pm 1.93$ & -0.027 & 0.979 \\
$\mathbf{1 2}^{\text {th }}$ week & $19.56 \pm 1.72$ & $20.0 \pm 1.73$ & -0.761 & 0.452 \\
$\mathbf{p}$ & $<0.001^{* *}$ & $<0.001 * *$ & & \\
\hline
\end{tabular}

F repeated measure ANOVA $\mathrm{t}$ Independent sample $\mathrm{t}$ test $* * \mathrm{p} \leq 0.001$ is statistically highly significant

Table (4): Comparison between the studied groups regarding CMT over time. 
Original article

CMT Groups
Ranibizumab group

Test

\begin{tabular}{lcccc}
\hline & Mean \pm SD & Mean \pm SD & & \\
Baseline & $414.11 \pm 130.44$ & $499.0 \pm 175.57$ & -1.63 & 0.113 \\
$\mathbf{1}^{\text {st }}$ week & $362.39 \pm 111.34$ & $448.0 \pm 144.62$ & -1.969 & 0.057 \\
$\mathbf{4}^{\text {th }}$ week & $315.28 \pm 89.82$ & $393.82 \pm 120.97$ & -2.19 & $0.036^{*}$ \\
$\mathbf{8}^{\text {th }}$ week & $280.0 \pm 75.23$ & $363.88 \pm 67.22$ & -2.529 & $0.016^{*}$ \\
$\mathbf{1 2}^{\text {th }}$ week & $251.44 \pm 67.22$ & $340.24 \pm 135.79$ & -2.473 & $0.019^{*}$ \\
$\mathbf{P}(\mathbf{F})$ & $<0.001 * *$ & $<0.001 * *$ & & \\
\hline F repeated measure ANOVA & t Independent sample t test $* * \mathrm{p} \leq 0.001$ is statistically highly significant $* \mathrm{p}<0.05$ is statistically
\end{tabular}
significant

Examble of a case in Ranibizumab group

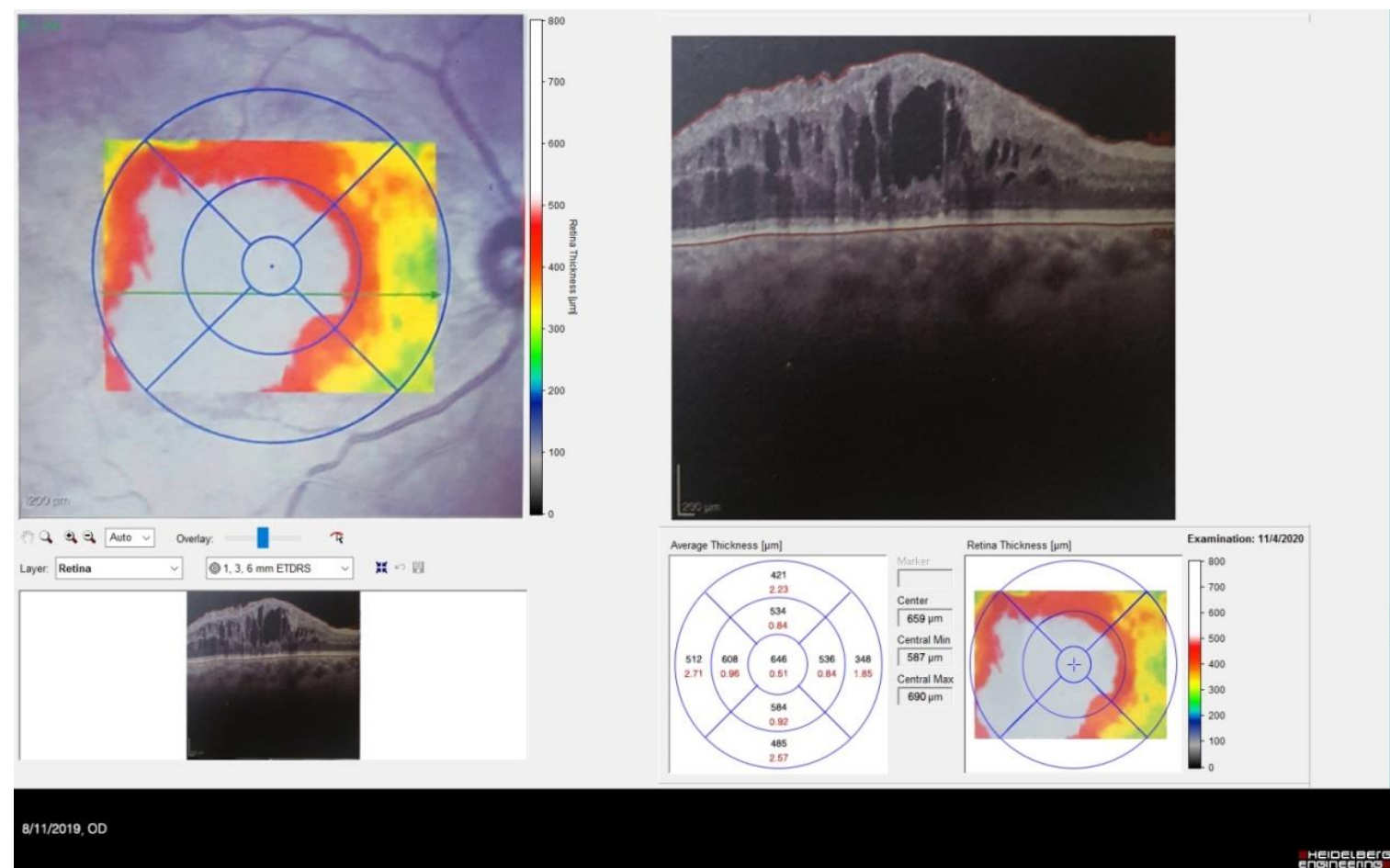

Fig. (1): OCT image of baseline CMT (646 um) in a patient with DME and ERM. 


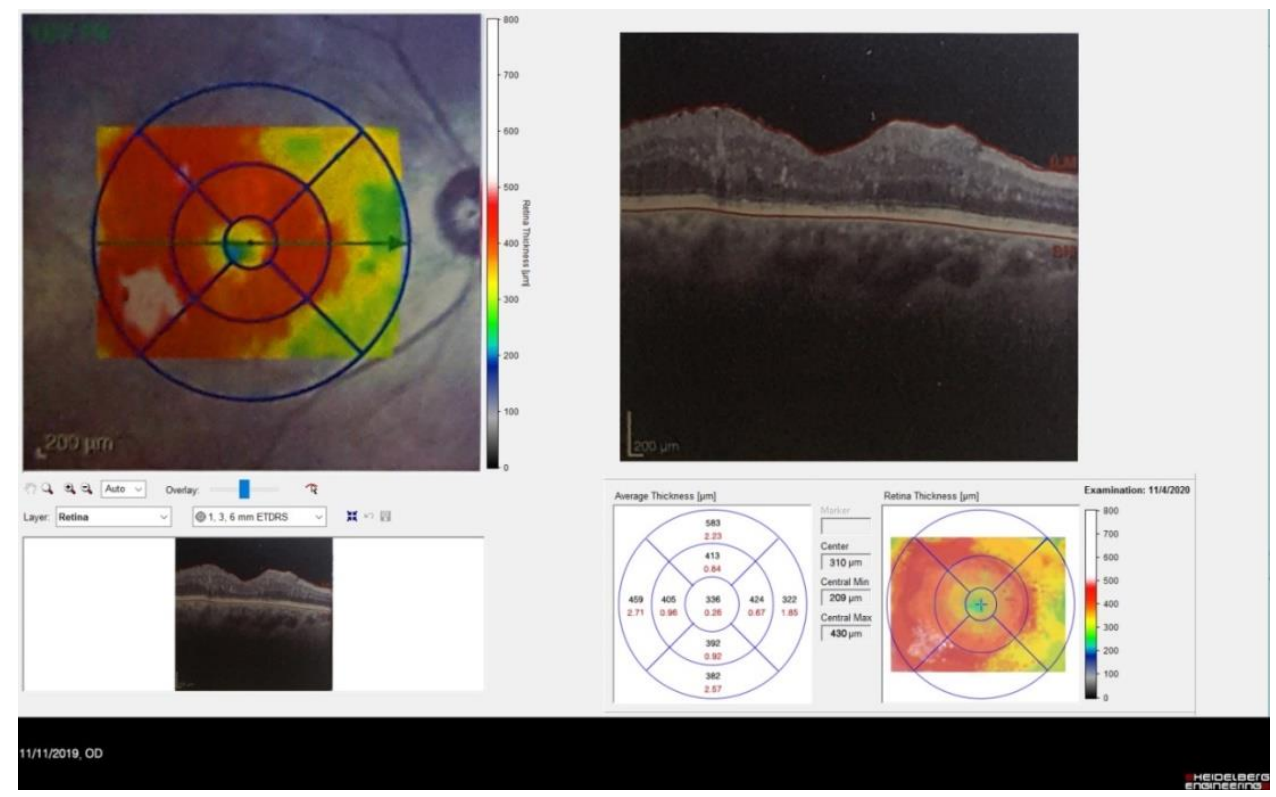

Fig. (2): OCT image of the same patient 12 weeks after receiving intravitreal injection of Ranibizumab, CMT reduced to (336 um).

Examble of a case in Triamcinolone acetonide group

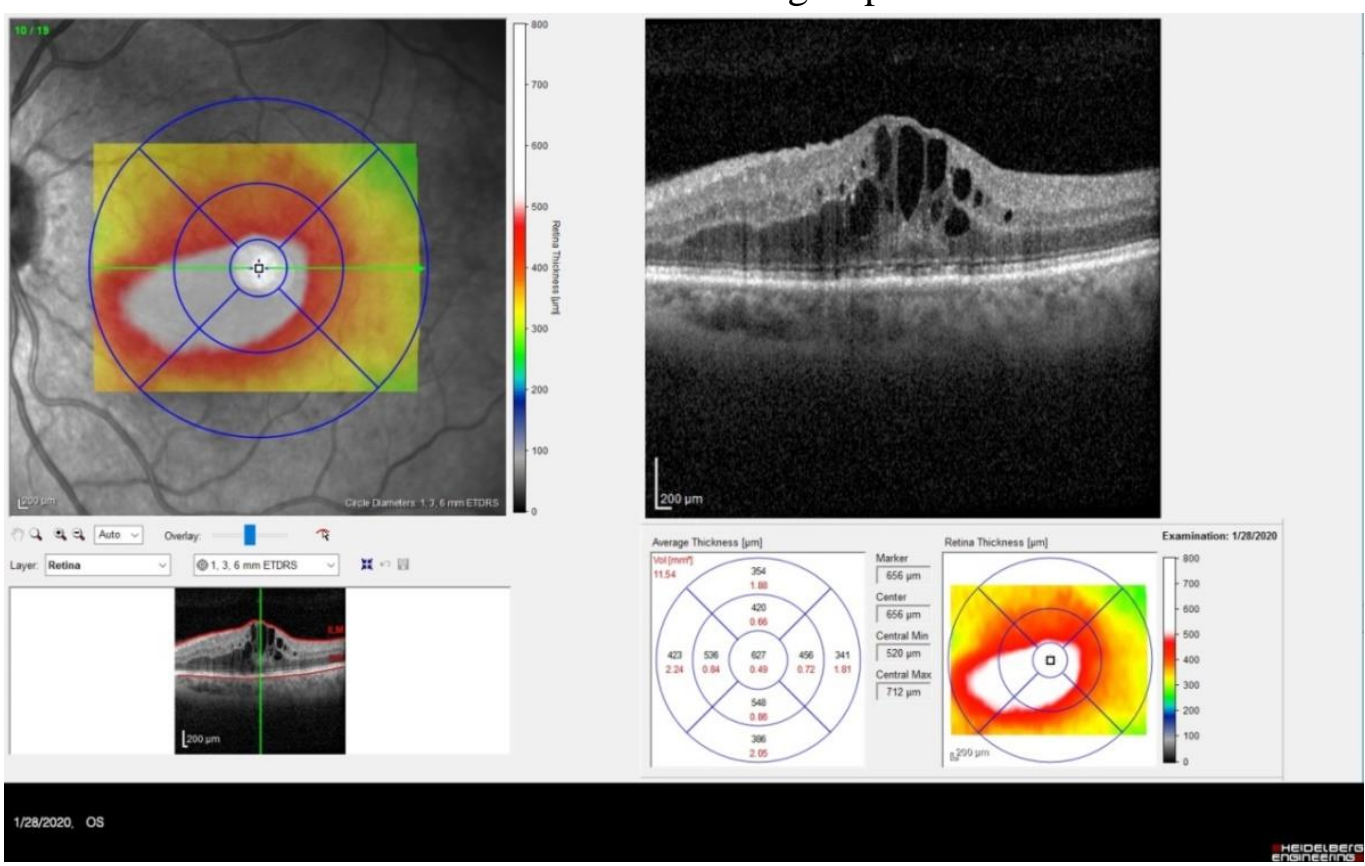

Figure (3): OCT image of baseline CMT (627 um) in another patient with DME and ERM. 

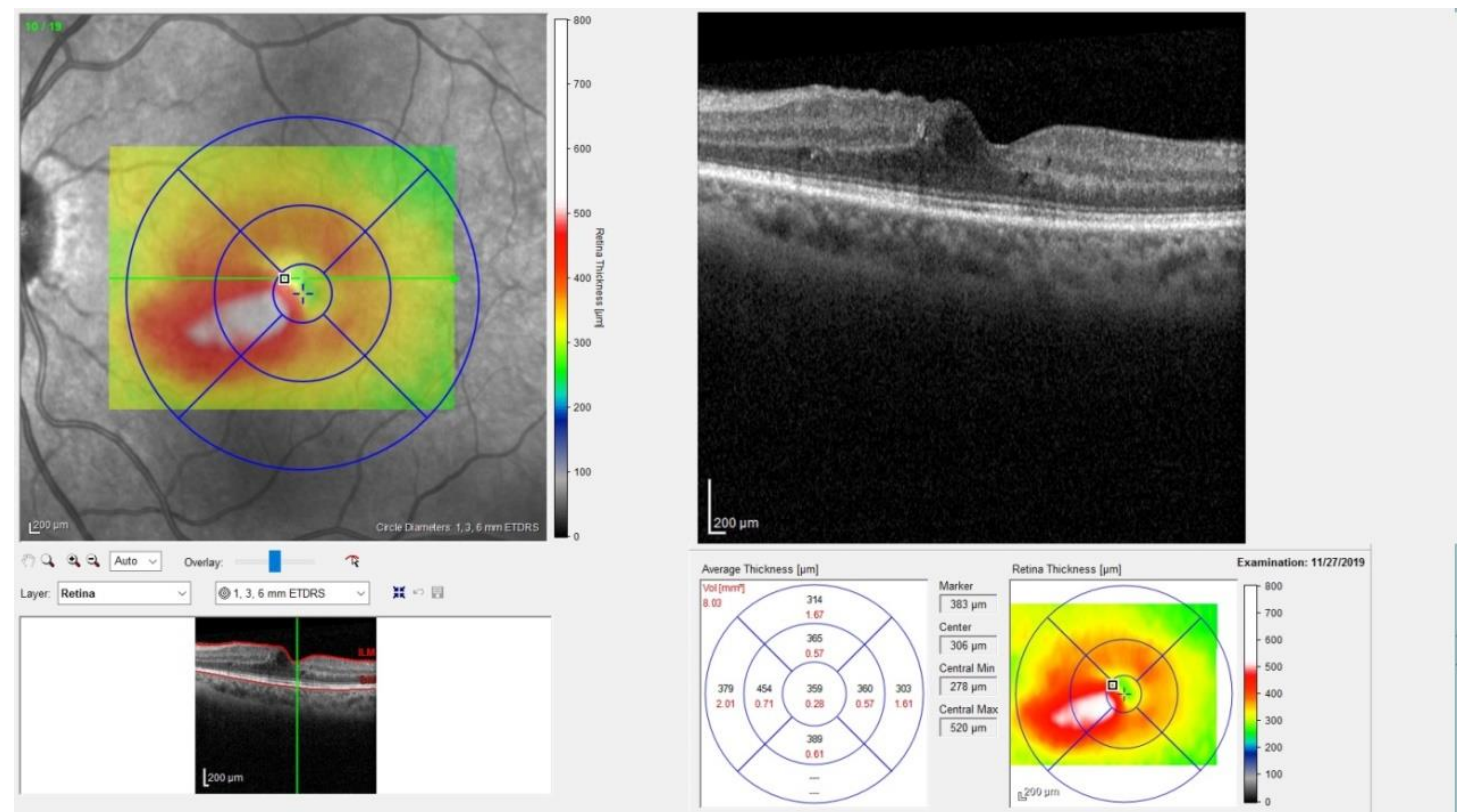

3/17/2020, OS

Figure (4): OCT image of the same patient 12 weeks after receiving intravitreal injection of Triamcinolone, CMT is (359 um).

\section{Discussion:}

We divided the patients into 2 groups;

- Ranibizumab group

- Triamcinolone acetonide group

In the present study 35 eyes of 28 patients were injected. Mean age of the patients was $62.25 \pm 7.15$ years in IVR group and $62.08 \pm 4.91$ years in IVTA group with the range of $48-72$ years. Out of the 35 eyes, 15 eyes were right $(42.8 \%)$ and 20 eyes were left $(57.2 \%)$.

BCVA improved from $0.5(0.3-1.4)$ to reach $0.2(0-0.9)$ at $12^{\text {th }}$ week postinjection in the Ranibizumab group and improved from 0.6 (0.5 $1.6)$ to $0.4(0.1-1.5)$ at $12^{\text {th }}$ week postinjection in Triamcinolone acetonide group $(\mathrm{p}<0.001)$.

IOP changed from baseline of $19.06 \pm$ 2.9 to $23.17 \pm 2.68$ at $1^{\text {st }}$ week reaching $19.56 \pm 1.72$ at $12^{\text {th }}$ week $(\mathrm{p}<0.001)$ in Ranibizumab group, and changed from baseline of $20.0 \pm 2.03$ to $23.76 \pm 2.31$ at 1 st week reaching $20.0 \pm 1.73$ at 12th week in Triamcinolone acetonide group ( $\mathrm{p}<0.001)$.

CMT changed from $414.11 \pm 130.44$ preinjection to $251.44 \pm 67.22$ at $12^{\text {th }}$ week postinjection in the Ranibizumab group, and changed from $499.0 \pm$ 175.57 preinjection to $340.24 \pm 135.79$ at $12^{\text {th }}$ week postinjection in 
Triamcinolone acetonide group (p $<0.001)$.

In $2009^{6}$, A study reported that CMT reduction was maintained until 3 months after IVTA injection, while in the IVB group, CMT reduction was maintained until two months after injection which is different from our study as they used Bevacizumab instead of Ranibizumab and our results showed that CMT reduction was maintained until three months in both IVTA and IVR group.

Another study in $2010^{7}$ also showed a significant reduction of CMT for at least three months ,the results of our study are in accordance with this study.

In the same way, according to a study in $2008^{8}$ which reported that a single IVTA had more effect on reduction of CMT in patients with DME compared with one intravitreal bevacizumab (IVB) during a 2-month period, more favorable BCVA improvement was observed with IVTA compared with that of IVB as early as one month after treatment and persisting up to 3 months in contrast to our study which showed equal effect of both drugs on CMT reduction.

On the other hand, Another study in $2018^{9}$, especially regarding CMT, reported that the CMT was found to be thinner in the Ranibizumab treated group than the Triamicinolone treated ones at 3 months in Karst study (2018). But this can be explained by different dose and regimen used to inject Ranibizumab in their study (three monthly injections of $0.5 \mathrm{mg}$ ranibizumab vs single injection of 0.5 mg ranibizumab in our study)

Our study showed different results to Karst study, as CMT has no statistical difference between IVTA group and IVR group but as mentioned before Karst study used to inject Ranibizumab in their study (three monthly injections of $0.5 \mathrm{mg}$ ranibizumab vs single injection of $0.5 \mathrm{mg}$ ranibizumab in our study

In a study held in $2009^{\mathbf{1 0}}$, showed that postoperative IS/OS junction status is related to the visual acuity after resolution of diabetic macular edema by vitrectomy. Retinal sensitivity has been used In $2011^{11}$ to objectively assess the macular function beside the analysis of BCVA, CMT, photoreceptor inner and outer segments (IS/OS) line. A study found retinal sensitivity after IVTA for DME to show, although relatively slow, significant improvement than did BCVA or CMT. The nasal quadrant of 
the macula showed more improvement than any other quadrant. In addition, a case with a discontinuous IS/OS line within $500 \mu \mathrm{m}$ from the center of the fovea showed significantly worse BCVA and retinal sensitivity at 2 degrees.

In another study in $2017^{\mathbf{1 2}}$ they have investigated the morphological changes and visual acuity response to ranibizumab therapy in patients with different OCT types of diabetic macular edema (DME) as well as different state of the inner and outer photoreceptor segments (IS and OS) and the external limiting membrane (ELM); to study the relationships between functional and morphological parameters before and after treatment with ranibizumab.

The most favorable type of DME in terms of preserving the integrity of photoreceptor segments and the ELM was sponge-like edema, while DME with neuroepithelial detachment together with mixed-type DME had unfavorable prognosis. The last two types prevented any statistically significant improvement of the main clinical factor - VA -even after complete reduction of the edema. These studies mentioned additional investigations in addition to CMT and
BCVA unlike in our study which uses CMT, IOP and BCVA.

\section{Conclusion:}

Both treatment types had good effect on reduction of CMT and improvement of BCVA. No postoperative complications have been recorded. Triamcinolone acetonide is much less expensive than Ranibizumab.

\section{References:}

1- Klein R, Klein BE, Moss SE, Cruickshanks $\boldsymbol{K} \boldsymbol{J}$. The Wisconsin epidemiologic study of diabetic retinopathy $\mathrm{XV}$ : the long-term incidence of macular edema. Ophthalmology. 1995 Jan 1;102(1):7-16.

2- Litvin TV, Bresnick GH, Cuadros JA, Selvin S, Kanai K, Ozawa GY. A revised approach for the detection of sightthreatening diabetic macular edema. JAMA ophthalmol. 2017 Jan 1;135(1):62-8.

3- Inagaki $K$, Hamada M, Ohkoshi $K$. Minimally invasive laser treatment combined with intravitreal injection of antivascular endothelial growth factor for diabetic macular oedema. Scientific reports. 2019 May 20;9(1):1-8.

4- Duh EJ, Sun JK, Stitt AW. Diabetic retinopathy: current understanding, mechanisms, and treatment strategies. JCI insight. 2017 Jul 20;2(14).

5- Aksoy S, Yilmaz, G, Akkoyun I, Yazici AC. Comparison of intravitreal bevacizumab and triamcinolone acetonide theraphies for diffuse diabetic macular edema. Int $\mathrm{J}$ Ophthalmol. 2015;8(3):550.

6- Oh SB, Moon JW, Kim HC. Comparison of effects of intravitreal triamcinolone and bevacizumab in the treatment of diabetic macular edema. J Korean Ophthalmol Soc. 2009;50(8):1190-6. 
7- Massin P, Bandello F, Garweg JG, Hansen $L L$, Harding SP, Larsen M, et al. Safety and efficacy of ranibizumab in diabetic macular edema (RESOLVE Study): a 12month, randomized, controlled, doublemasked, multicenter phase II study. Diabetes care. 2010 Nov 1;33(11):2399-405.

8- Paccola L, Costa RA, Folgosa MS, Barbosa $J C$, Scott IU, Jorge R. Intravitreal triamcinolone versus bevacizumab for treatment of refractory diabetic macular oedema (IBEME study). Br J Ophthalmol. 2008;92(1):76-80.

9- Karst SG, Lammer J, Mitsch C, Schober M, Mehta J, Scholda C, et al. Detailed analysis of retinal morphology in patients with diabetic macular edema (DME) randomized to ranibizumab or triamcinolone treatment. Graefes Arch Clin Exp Ophthalmol. 2018;256(1):49-58.
10- Sakamoto A, Nishijima K, Kita M, Oh H, Tsujikawa A, Yoshimura N. Association between foveal photoreceptor status and visual acuity after resolution of diabetic macular edema by pars plana vitrectomy. Graefes Arch Clin Exp Ophthalmol. 2009;247(10):1325-30.

11- Kameda T, Nishijima $K$, Unoki $N$, Sakamoto A, Hayashi $\mathrm{H}$, Oh $\mathrm{H}$, et al. Geographic pattern of central retinal sensitivity after intravitreal triamcinolone for diabetic macular edema. Graefes Arch Clin Exp Ophthalmol. 2011;249(1):3-9.

12- Fursova AZ, Chubar NV, Tarasov MS, Saifullina IF, Pustovaya GG. Clinical associations between photoreceptor status and visual outcomes in diabetic macular edema. Vestn Oftalmol. 2017 Jan 1;133(1):11-8.

o cite this article: Ahmed E. Daifalla, Ahmed A. Tabl, Marwa A. ElFouly, Mohamed M. Rezk. Comparison of the Effect of Ranibizumab and Triamcinolone Acetonide in Diabetic Macular Edema with Epiretinal Membrane in Pseudophakic Patients. BMFJ 2022; 39 (ophthalmology):38-48. DOI: 10.21608/bmfj.2021.80398.1425 
